\title{
Nanocomposite glass coatings containing hexagonal boron nitride nanoparticles
}

\author{
H. Erdem Çamurlu ${ }^{\mathrm{a}, *}$, Esin Akarsu ${ }^{\mathrm{b}}$, Osman Arslan ${ }^{\mathrm{c}}$, Sanjay Mathur ${ }^{\mathrm{d}}$ \\ ${ }^{a}$ Akdeniz University, Mechanical Engineering Department, 07058 Antalya, Turkey \\ ${ }^{\mathrm{b}}$ Akdeniz University, Faculty of Science, Chemistry Department, 07058 Antalya, Turkey \\ c Bilkent University UNAM, Bilkent, 06800 Ankara, Turkey \\ d Institute of Inorganic Chemistry, University of Cologne, Greinstrasse-6, d-50939 Cologne, Germany
}

\section{A R T I C L E I N F O}

\section{Article history:}

Received 1 February 2016

Received in revised form

22 February 2016

Accepted 23 February 2016

Available online 24 February 2016

Keywords:

Glass coating

Hexagonal boron nitride

Sol-gel

Nanocomposite coating

\begin{abstract}
A B S T R A C T
Glass coatings composed of $\mathrm{SiO}_{2}-\mathrm{K}_{2} \mathrm{O}-\mathrm{Li}_{2} \mathrm{O}$, containing non-modified and fluorosilane modified hexagonal boron nitride (hBN) nanoparticles, were prepared on stainless steel plates through sol-gel spincoating method. Coatings were examined by scanning electron microscopy (SEM), Fourier transform infrared (FTIR) spectroscopy, x-ray diffraction (XRD), atomic force microscopy (AFM) and thermogravimetric analysis (TGA). $1.3-2.5 \mu \mathrm{m}$ thick uniform coatings were obtained after curing at $500{ }^{\circ} \mathrm{C}$ for $1 \mathrm{~h}$. The coatings adhered well to the steel substrates. It was determined by salt spray tests that the coatings enhance corrosion resistance. The aim of hydrophobic fluorosilane modification of hBN nanoparticles was to enrich hBN quantity on the top surface of the coatings. Coatings containing fluorosilane modified hBN nanoparticles presented slightly lower friction coefficient values than the other coatings. (c) 2016 Elsevier Ltd and Techna Group S.r.l. All rights reserved.
\end{abstract}

\section{Introduction}

Well-adhered glass coatings formed via sol-gel technique on metal substrates can offer various attributes such as corrosion protection, scratch or abrasion resistance, anti-bacterial property [1] and water or oil repellence, etc. [2,3]. When coated, maintenance or replacement durations of the components increase in addition to improvement of the components properties like resistance to corrosion and wear, and lower friction coefficient [4].

Up-to-date, various kinds of nanoparticles such as $\mathrm{TiO}_{2}, \mathrm{SiO}_{2}$, $\mathrm{Al}_{2} \mathrm{O}_{3}$ and $\mathrm{ZrO}_{2}$ have been introduced into numerous types of matrices via sol-gel technique for obtaining functional nanocomposite coatings [5-9]. Although there has been extensive attention on applications of hexagonal boron nitride (hBN) in any form, there is limited research on its utilization in coatings. Crystal structure and some of the properties of hBN resemble to those of graphite. hBN is an electrical insulator and it has high oxidation temperature (over $800^{\circ} \mathrm{C}$ ) in powder form, low thermal expansion and low friction coefficient, and it is resistant to thermal shock [10-17].

In literature, monolithic coatings of hBN were prepared through magnetron sputtering [18] or CVD techniques [19-20]

\footnotetext{
* Correspondence to: Akdeniz Üniversitesi, Makine Mühendisliği Bölümü, Dumlupınar Bulvarı, Kampüs, 07058 Antalya, Turkey.

E-mail address: erdemcamurlu@gmail.com (H.E. Çamurlu).
}

with the aim of decreasing friction coefficient or improving oxidation resistance. Chong et al. [19] reported that friction coefficients as low as $0.10-0.15$ could be obtained by hBN coatings. Ultrathin hBN coatings were obtained for oxidation resistance via CVD by Liu et al. [21]. Requirement of expensive equipment, high vacuum, hazardous precursors and ability to produce only small area coatings are the disadvantages of these methods. Monolithic BN coatings were reported to wear off quickly during contact sliding due to the very low hardness of hBN [19]. Therefore, utilization of hBN particles in a harder matrix in the form of a composite coating seems as a better choice for higher wear resistance.

In the study of Hou et al. [22] hBN microparticles were modified with silanes and they were utilized in epoxy matrix composites. A significant increase in the thermal conductivity was reported when $30 \%$ hBN was used. hBN-PVA coatings were produced for marine corrosion protection [23]. hBN particles were utilized also in metal matrix composites [24-26]. Nickel [24,25] and nickel aluminide [26] matrix composite coatings containing hBN were formed through electroless deposition [24], laser melting [25], reactive sintering [26] and cold spray [4]. A decrease in wear rate and a friction coefficient of about 0.20 were reported in the obtained composite coatings [24].

Although various techniques can be utilized for obtaining thin films and coatings, such as thermal spray, physical and chemical vapor and other deposition techniques, sol-gel method brings the possibility of obtaining functional coatings in nanometer or 

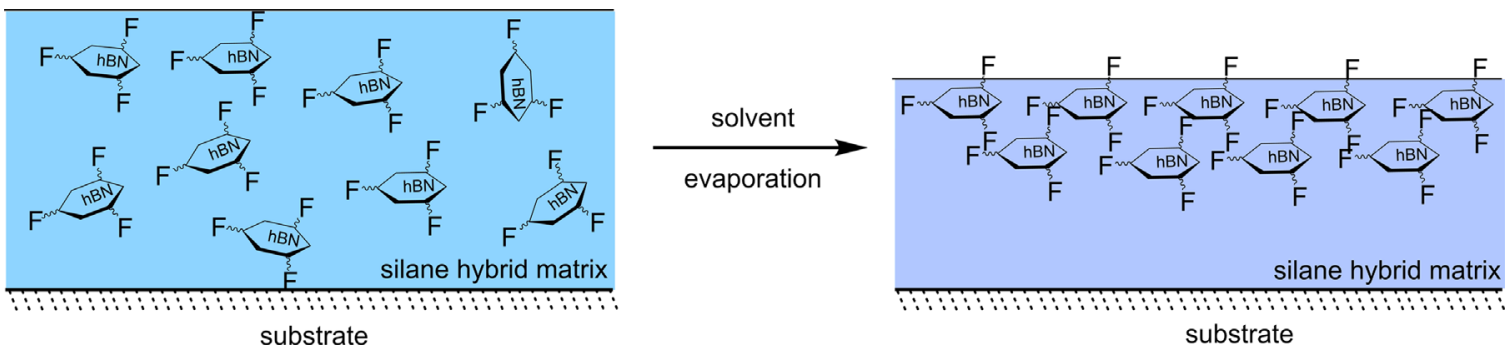

Fig. 1. Schematic representation of migration of surface fluorinated hBN nanoparticles to the surface of the glass coatings.

micrometer thickness on the large area surfaces of various types of materials. In addition, it is an ideal process for preparation of nanocomposite coatings having organic or inorganic matrices [2733]. In the sol-gel process, molecular scale mixing of precursors is achieved in a solvent at low temperature, which provides the good dispersion of nanometer sized reinforcement phase or the formation of organized structures like functionally graded materials [5]. Thus, sol-gel technique is increasingly used in the formation of functional and nanocomposite coatings due to its advantages over other techniques such as requiring fewer and cheaper instruments, being simpler and more economical and providing more control on structure of the coating [5,27-34]

Most of the research on sol-gel is based on silicon containing systems [5]. A polymeric or particulate sol, obtained through hydrolysis and condensation reactions of alkoxides, can be applied to the surface in the form of spray, spin or dip coating. Parameters, such as type of solvent, viscosity of sol and coating method can be altered in order to adjust the properties of the coatings. Low curing temperatures result in organic-inorganic hybrid structures, whereas high curing temperatures yield an inorganic film $[5,30,34]$. On glass surfaces, functional coatings such as antireflective [28-30] and self-cleaning coatings [30-33] have been produced by sol-gel dip-coating method.

Preferential accumulation of $\mathrm{TiO}_{2}$ particles to the surface of the coating has been investigated previously $[7,8]$. This is achieved through modification of the particles with fluorosilanes. They have intrinsically very low surface energies [36] and they possess hydrophobic property. The surface energy of the particles is lowered by fluorosilane molecules on them. This creates the discrepancy between the surface energies of modified particles and the coating matrix. As the solvent evaporates, migration of the particles to the surface of the coating is expected to be induced thermodynamically. The decompatibility between the hydrophilic solution and hydrophobic molecules on the particles results in the segregation of the particles to the coating-air interface [7]. Zhu et al. [8] prepared hybrid multilayer coatings by utilizing fluorinated $\mathrm{TiO}_{2}$ particles in poly(lactic acid) (PLA) films. They have found that concentration of $1 \mathrm{H}, 1 \mathrm{H}, 2 \mathrm{H}, 2 \mathrm{H}$-perfluorooktyl-triethoksysilane (FTS) modified $\mathrm{TiO}_{2}$ particles were richer on the aircoating interface, as compared to non-modified particles. This resulted in higher photocatalytic activity [8]. With the similar aim, Schmidt et al. [7] applied photocatalytic gradient silica based coatings on plastics by sol-gel technique. These coatings contained $\mathrm{TiO}_{2}$ nanoparticles, surfaces of which were modified by a silane containing fluoro-organic side chain (FTS). The modified $\mathrm{TiO}_{2}$ nanoparticles were observed to diffuse to the coating-air interface. This resulted in a gradient layer formation, with high $\mathrm{TiO}_{2}$ concentration on the coating-air interface [7]. Silica and bisphenol-A epoxy resin based ceramers were produced by Mascia et al. [36]. Perfluoroether oligomer was used in order to modify the epoxy ceramers. Considerable reduction in the surface energy was obtained due to the extensive migration of perfluoroether to the surface [36]. Similarly, organic-inorganic hybrids containing perfluoropolyether (PFPE) were obtained by Fabbri et al. [35]. PFPE segments were seen to segregate to the surface, which resulted in a strong hydrophobic and lipophobic character. This was attributed to very low surface energy of PFPE [35].

In the present study, glass nanocomposite coatings containing hBN nanoparticles were prepared through sol-gel method. To the best of our knowledge, this type of coating has not been investigated previously. In our previous study, surfaces of the hBN nanoparticles were modified with $1 \mathrm{H}, 1 \mathrm{H}, 2 \mathrm{H}, 2 \mathrm{H}$-perfluorooktyltriethoksysilane (FTS) for rendering the hBN nanoparticles surfaces hydrophobic [37]. The aim of hydrophobic modification is to position the hBN nanoparticles on the outermost layer of the hydrophilic coating solution by a self-organizing process during solvent evaporation as shown in Fig. 1, in analogy with the cases that were shown for different kinds of nanoparticles [6-8]. The formed structure is expected to improve the friction properties of the coating.

\section{Experimental procedure}

Stainless steel plates were coated with glass composition consisting of $\mathrm{SiO}_{2}, \mathrm{Li}_{2} \mathrm{O}$ and $\mathrm{K}_{2} \mathrm{O}(\% 85, \% 5$ and \%15) via sol-gel spincoating. For the preparation of hBN containing films, hBN nanoparticles were dispersed with $2 \mathrm{~mm}$ or $400 \mu \mathrm{m}$ diameter zirconia beads in methoxy propanol (MP, ABCR) via a wet dispersing machine at $2000 \mathrm{rpm}$ (Yokes) and they were added into the coating solution. In some coatings, hBN nanoparticles which were modified with $1 \mathrm{H}, 1 \mathrm{H}, 2 \mathrm{H}, 2 \mathrm{H}$-perfluorooktyl-triethoksysilane (FTS) (ABCR, 95\%), were used. Surface modification of hBN nanoparticles was carried out at $150^{\circ} \mathrm{C}$ for $2 \mathrm{~h}$ under reflux condenser in MP [37].

For the preparation of the sol, tetraethoxysilane (TEOS, 99\%, Aldrich) (14.99 g), methyltriethoxysilane (MTEOS, 99\% Aldrich) (3.75 g), lithium hydroxide ( $\mathrm{LiOH}, 98 \%$, Merck) $(1.80 \mathrm{~g})$, potassium hydroxide ( $\mathrm{KOH}, 84 \%$ Merck) (3.127 g) were mixed overnight. For hydrolysis, $6.47 \mathrm{~g} \mathrm{H}_{2} \mathrm{O}$ and $32.35 \mathrm{~g}$ ethyl alcohol were mixed and added to the sol. hBN nanoparticles (M.K. Impex Corp., average diameter, $70 \mathrm{~nm}$ ) were introduced into the coating solution in 2 wt\% solid ratio.

AISI 304 stainless steel sheets were cut in $50 \times 50 \times 0.8 \mathrm{~mm}^{3}$ dimensions to form the substrates. Their surfaces were prepared by washing with detergent (Henkel, P3), rinsing with distilled water and neutralizing in aqueous $\mathrm{HNO}_{3}(10 \%, \mathrm{w} / \mathrm{w})$. The plates were coated by spin coating at $500 \mathrm{rpm}$ and $750 \mathrm{rpm}$. Curing was conducted at $500{ }^{\circ} \mathrm{C}$ for $1 \mathrm{~h}$ (Nabertherm LH 30/12).

MPO0 model Fischer Dualscope was used for measuring the thickness of the coatings. Adhesion tests were performed by Erichsen Type 295 multi-cross cutter (ASTM D 3359 WK97). Surface hardness of the films was measured by an Erichsen Hardness Test Pencil 318, which involves a spring loaded tip. In this study, the size and material of the tip of the used stylus were $0.75 \mathrm{~mm}$ and tungsten carbide, respectively (Bosch method). In this technique, the known spring tension is set (in 0-20N range), the tip of the instrument is placed on the test surface and a $10 \mathrm{~mm}$ long line 
is drawn. At a certain force, the stylus produces a scratch which is just visible with the naked eye. This critical value of force is expressed as the hardness of the coatings in Newton. ATR-FTIR, Varian 1000 Fourier transform infrared spectrophotometer was used for FTIR analyses. Surfaces and cross sections of the glass coatings were examined by scanning electron microscope (SEM) (FEI Nova NanoSEM). For cross sectional analyses in SEM, coatings were prepared on the surfaces of silicon wafers, instead of stainless steel plates, in order to provide brittle fracture of the substrate. Surfaces of the coatings were investigated by atomic force microscopy (AFM) (PSIA XE-100E). Friction coefficients were measured by an oscillating tribometer (Tribotechnic). Water contact angles were measured with a goniometer (RAME-HART 10000 ). Thermogravimetric analyses (TGA) were performed with a Mettler Toledo unit. Erichsen Corrotherm 610 cabin was used for corrosion resistance tests.

\section{Results and discussion}

\subsection{FT-IR, TGA and XRD analyses}

Glass coating solutions were prepared by mixing TEOS, MTEOS, $\mathrm{KOH}$ and $\mathrm{LiOH}$ at proper ratios. FT-IR spectra of the hydrolyzed solution and the coating obtained after curing at $500{ }^{\circ} \mathrm{C}$ are presented in Fig. 2. The wide band at $3400 \mathrm{~cm}^{-1}$ corresponds to $-\mathrm{OH}$ asymmetric stretching [38]. During hydrolysis, -OR groups in TEOS and MTEOS exchange with - $\mathrm{OH}$ groups. The presence of the $-\mathrm{OH}$ groups indicates the hydrophilic character of the sol. The peaks at $2800-3000 \mathrm{~cm}^{-1}$ and at $1400-1500 \mathrm{~cm}^{-1}$ belong to $\mathrm{C}-\mathrm{H}_{x}$ stretching and bending vibrations, respectively [38]. Si-O-Si asymmetric stretching peaks are at $1000-1100 \mathrm{~cm}^{-1}$. The peak at $950 \mathrm{~cm}^{-1}$ is assigned to $\mathrm{Si}-\mathrm{OH}$ stretching. Si-O-Si symmetric stretching peak is at $800 \mathrm{~cm}^{-1}$. After curing at $500{ }^{\circ} \mathrm{C}$, peaks pertaining to $\mathrm{H}_{2} \mathrm{O}$ and EtOH and other organic groups are removed. In the cured coating, the maintenance of strong absorption peaks at $1000-1100 \mathrm{~cm}^{-1}$ and at $800 \mathrm{~cm}^{-1}$ due to $\mathrm{Si}-\mathrm{O}-\mathrm{Si}$ asymmetric and symmetric stretchings, respectively, indicate the presence of the silica network.

Thermal behavior of the coatings was evaluated by TGA under flowing nitrogen. TGA thermograms of hydrolyzed sol and of the coating cured at $500{ }^{\circ} \mathrm{C}$ are presented in Fig. 3. The weight loss of the hydrolyzed sol takes place in two steps. The first step between 25 and $200{ }^{\circ} \mathrm{C}$ is due to alcohol and water evaporation in the sol. The second step between $450{ }^{\circ} \mathrm{C}$ and $600{ }^{\circ} \mathrm{C}$ is due to

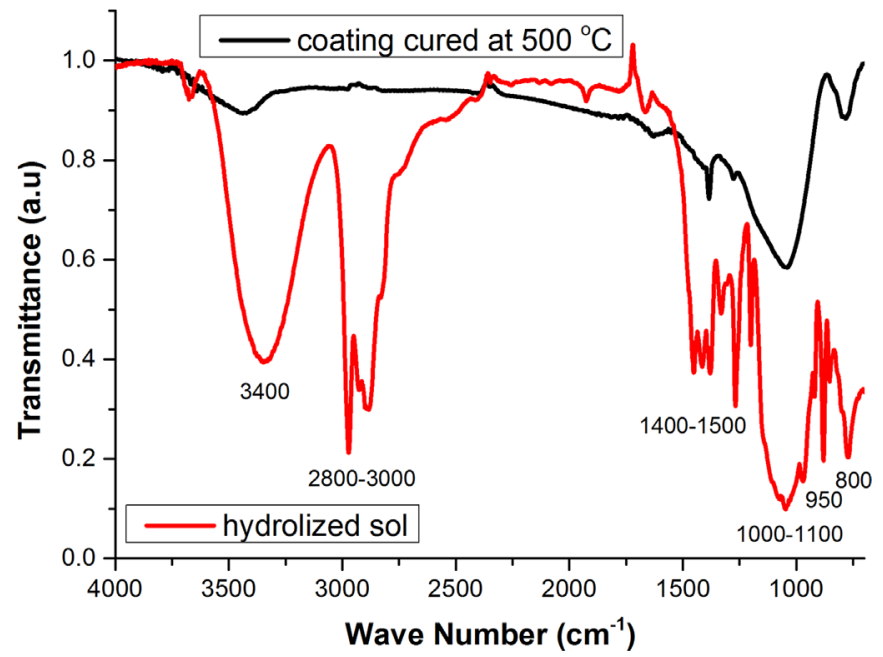

Fig. 2. FT-IR spectra of hydrolyzed sol and the cured coating at $500{ }^{\circ} \mathrm{C}$.

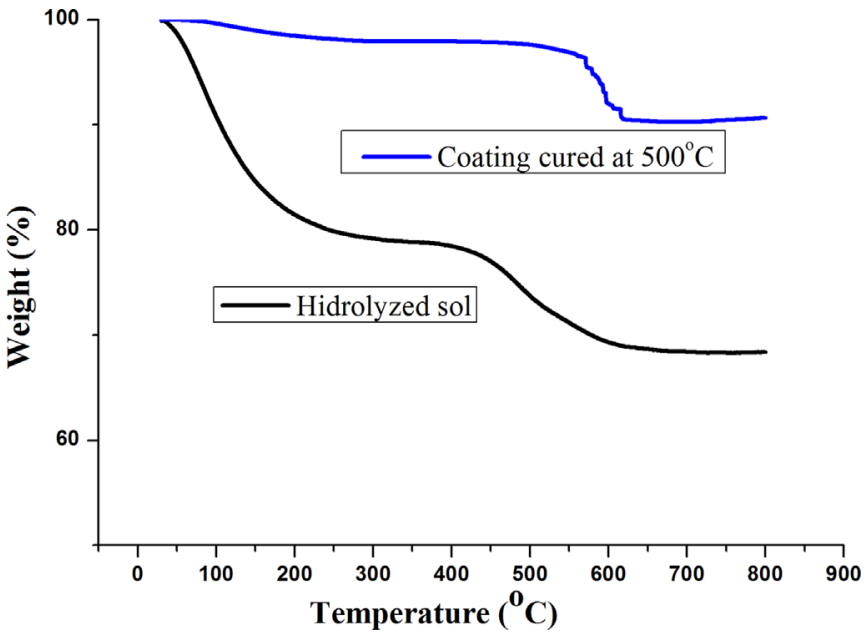

Fig. 3. TGA thermograms of hydrolyzed sol and the cured coating at $500{ }^{\circ} \mathrm{C}$.

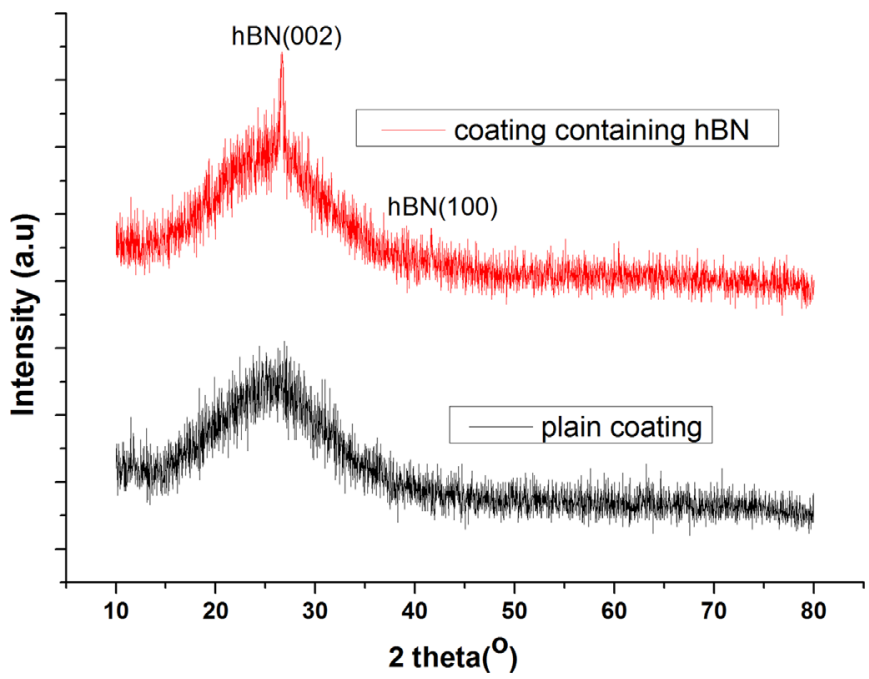

Fig. 4. XRD patterns of (a) the plain coating, and (b) the coating containing hBN after curing at $500{ }^{\circ} \mathrm{C}$.

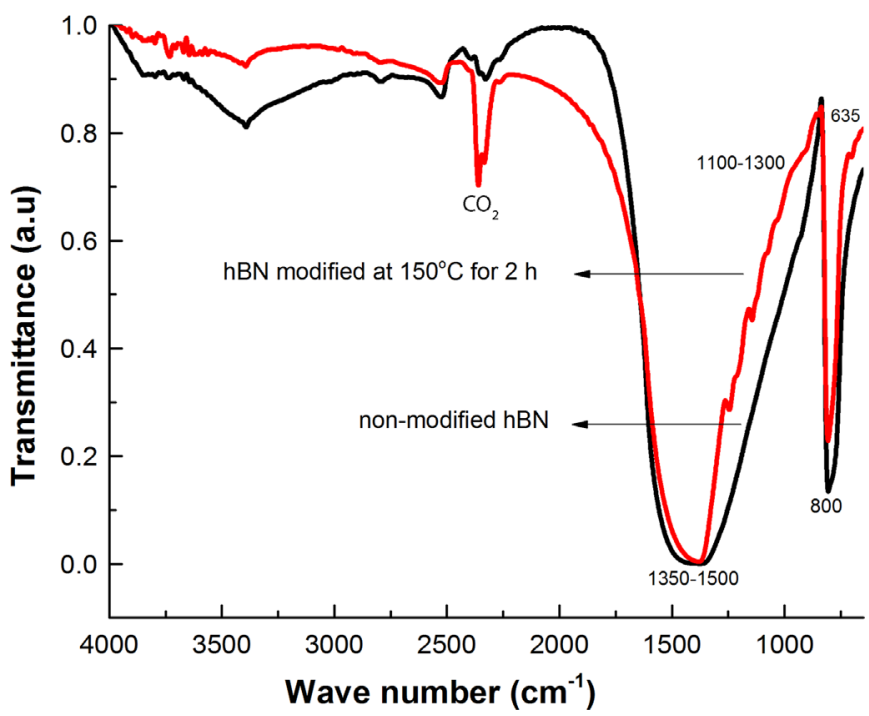

Fig. 5. FT-IR spectra of non-modified and modified hBN nanoparticles. 


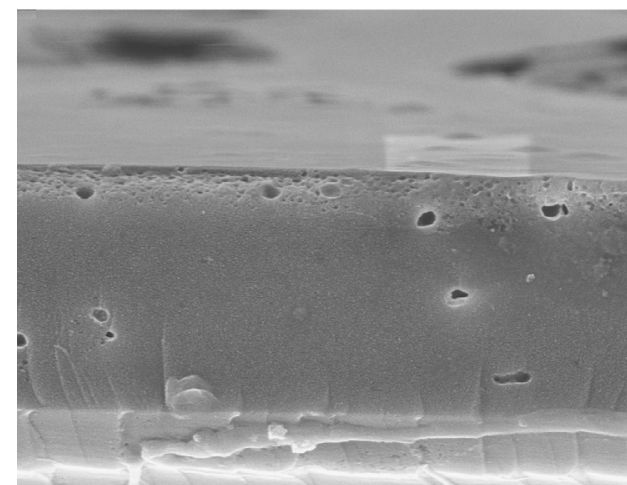

(a)
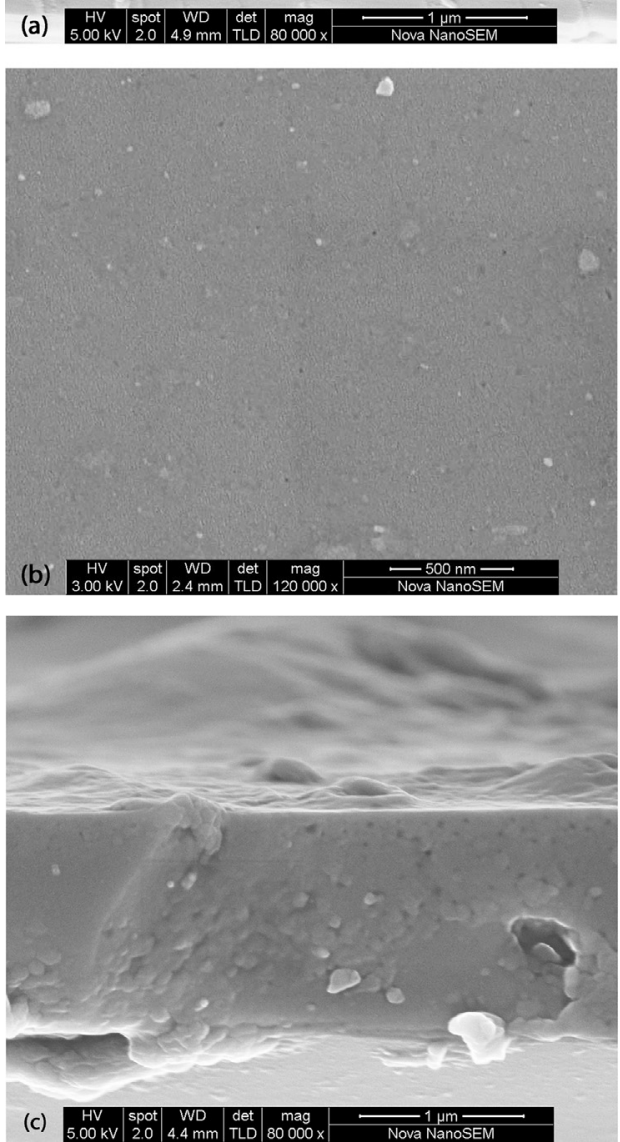
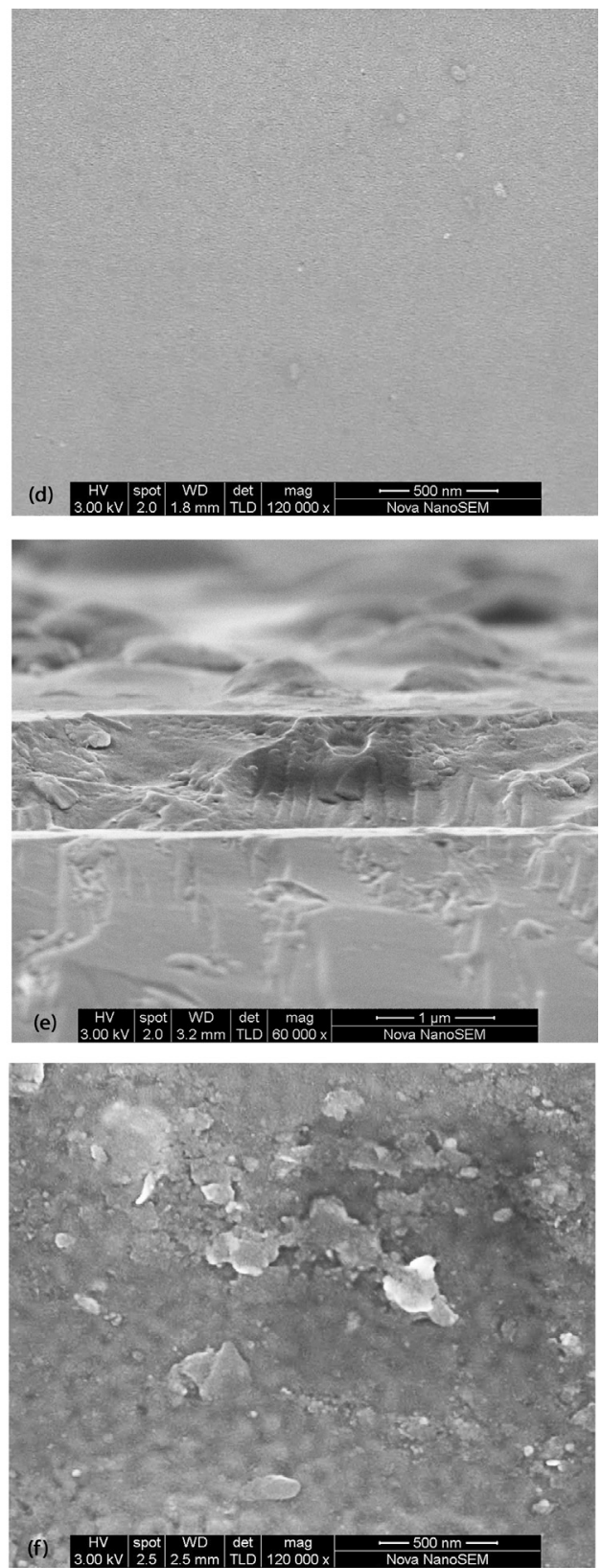

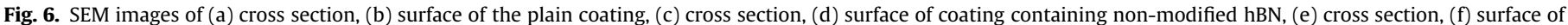
coating containing modified hBN.

decomposition of the organic groups in the system [8]. For the coating which was cured at $500{ }^{\circ} \mathrm{C}$, the first step of weight loss corresponding to alcohol and water evaporation is not present. The starting point of the second step shifted to temperatures over $500{ }^{\circ} \mathrm{C}$ and the weight loss in this step decreased. This is predictable since some of the organic groups are expected to decompose during curing at $500{ }^{\circ} \mathrm{C}$, leaving a glass network.

Glass coatings that do not contain hBN (plain coatings) and coatings containing hBN were prepared by spin coating the steel plates with the sol and then by heating the coated plates for curing. XRD patterns of the plain coating and of the coating containing hBN after curing at $500{ }^{\circ} \mathrm{C}$ are presented in Fig. 4. It can be seen that both of the coatings have amorphous structure. The broad peak between $20^{\circ}$ and $30^{\circ}$ is characteristic of amorphous silica [38]. In the XRD pattern of the coating containing hBN, peaks pertaining to hBN crystal structure are present. It can be inferred from these results that glass films containing hBN were obtained.
For modification of the hBN nanoparticles with FTS, hBN nanoparticles were dispersed with zirconia beads in a wet dispersing machine with FTS addition at FTS/hBN weight ratio of 1.5 . The dispersed nanoparticles were modified with FTS in methoxy propanol for $2 \mathrm{~h}$ at $150{ }^{\circ} \mathrm{C}$, in a reflux condenser. After rinsing and centrifuging, they were dried in a rotary evaporator [37]. Modified and non-modified hBN nanoparticles were subjected to FT-IR analyses and the results are presented in Fig. 5. In both of the FT-IR spectra, the peaks at $800 \mathrm{~cm}^{-1}$ and at $1350-1500 \mathrm{~cm}^{-1}$ correspond to out-plane bending of $\mathrm{B}-\mathrm{N}-\mathrm{B}$ bonds, and in-plane stretching of B-N bonds, respectively [39], and the ones at 3200$3400 \mathrm{~cm}^{-1}$ are due to $\mathrm{O}-\mathrm{H}$ groups in the structure [40]. In the FTIR spectrum of modified hBN, stretchings at $1100-1300 \mathrm{~cm}^{-1}$ and at $635 \mathrm{~cm}^{-1}$ are due to fluor bearing groups $\left(-\mathrm{CF}_{2}\right.$ and $-\mathrm{CF}_{3}$, respectively) [41]. The presence of FTS molecules on hBN nanoparticles indicate that fluorosilane modification was accomplished [37]. Modified hBN nanoparticles were introduced into the coating 

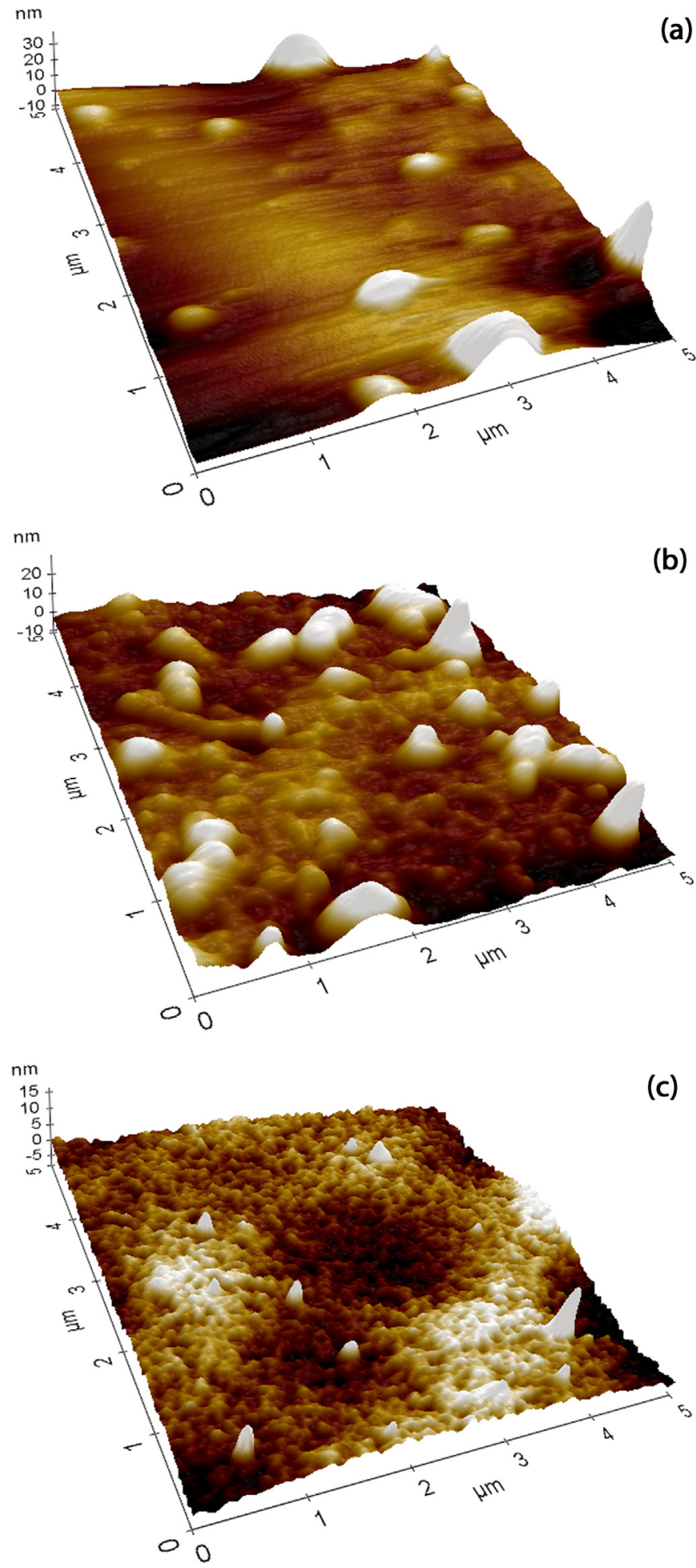

Fig. 7. AFM images of (a) plain coating, (b) coating containing non-modified hBN, and $(\mathrm{c})$ coating containing modified hBN.

solutions and coatings containing modified hBN were obtained by the same procedure as the coatings containing non-modified hBN.

\subsection{SEM and AFM examinations}

Initially, SEM examinations were attempted on the cross sections of the coatings which were prepared on stainless steel substrates. However, coatings could not be examined properly, since they were peeled off from the substrate during cutting the metal
Table 1

Properties of the plain coatings, coatings containing non-modified hBN, and coatings containing modified hBN nanoparticles.

\begin{tabular}{llllllll}
\hline $\begin{array}{l}\text { hBN } \\
\text { ratio }\end{array}$ & SCS (rpm) & hBN surface & WCA $\left({ }^{\circ}\right)$ & COF & T $(\mu \mathbf{m})$ & \pm & H $(\mathbf{N})$ \\
\hline- & 750 & - & 9 & $0.15-0.2$ & 1.27 & 0.09 & 2 \\
$\% 2$ & 500 & $\begin{array}{l}\text { Non- } \\
\text { modified }\end{array}$ & 9 & $0.1-0.2$ & 1.83 & 0.08 & 3.5 \\
$\% 2$ & 750 & $\begin{array}{l}\text { Non- } \\
\text { modified } \\
\text { Modified }\end{array}$ & 8 & $0.1-0.2$ & 1.37 & 0.09 & 3.5 \\
& 500 & 10 & $0.1-0.15$ & 2.49 & 0.34 & 2 \\
\hline
\end{tabular}

SCS: Spin Coating Speed (rpm), WCA: Water Contact Angle $\left(^{\circ}\right)$, COF: Coefficient of Friction, T: Thickness $(\mu \mathrm{m}), \mathrm{H}$ : Newton Hardness (Newton)

plate. The edges of the steel plate plastically deform and the coating on that region cracks and peels off while cutting the plate for sample preparation for SEM. Therefore, in order to provide brittle fracture of the substrate and the coating, the coatings to be observed in SEM were prepared on silicon wafer substrates by spin coating.

SEM micrographs of the cross section and the surface of plain coating are presented in Fig. 6(a) and (b), respectively. It can be seen in Fig. 6(a) that the coating is homogenous and it contains spherical and isolated pores, which are mostly smaller than $100 \mathrm{~nm}$. These pores are suggested to form due to solvent evaporation. The coating is crack-free. The thickness of the coating is observed as about $1.5 \mu \mathrm{m}$, which is consistent with values obtained from the thickness measurements. The surface of the coating is smooth, as can be seen in Fig. 6(b). The thickness of the coating containing non-modified hBN can be seen as 1-1.5 $\mu \mathrm{m}$ in Fig. 6(c). The surface of this coating is also smooth (Fig. 6(d)). The thickness of the coating containing modified hBN nanoparticles was about $1 \mu \mathrm{m}$ (Fig. 6(e)). The surface of this coating (Fig. 6(f)) is different from plain coating and from coating containing nonmodified hBN. hBN nanoparticles are believed to be located on the uppermost layer of the coating. It was seen during SEM examinations that there are some spots where hBN nanoparticles are gathered, on the surface of the coating. Sizes of these spots are a few hundred nanometers. hBN nanoparticles appear to be sticking out of the coating on these spots. This may be due to the hydrophobic modification of the hBN nanoparticles. As a result of the hydrophobic fluorosilane molecules on the surfaces of the hBN nanoparticles, they are expected to be positioned on the top surface of the coatings $[7,8,35]$. This is believed to be due to the low surface energy of fluorosilane. The FTS molecules tend to segregate to the coating-air interface, thereby the hBN nanoparticles migrate to the surface of the coating. This results in the enrichment of the hBN concentration on the coating surface.

AFM images of the surfaces of the plain glass coating, of coating containing non-modified hBN, and of coating containing modified hBN are presented in Fig. 7(a), (b) and (c), respectively. The surfaces of the plain coatings were seen to be smooth on the AFM images. This result is in agreement with the SEM observations. There were some asperities on these coatings, which were about $30 \mathrm{~nm}$ high and half micrometer in diameter. These asperities were more intense in the coating containing non-modified hBN. Thus, some of these may originate from the agglomeration of hBN nanoparticles in the coating solution. Coatings containing modified hBN had less number of large asperities as compared to the other two types of coatings. This may be due to better dispersion of hBN nanoparticles, with the effect of FTS molecules on their surfaces. Moreover, there were much smaller asperities, which were about $5 \mathrm{~nm}$ high and $100 \mathrm{~nm}$ in diameter. These smaller asperities were not present on plain coatings, and they were present in fewer amounts in coatings containing non-modified 
$\mathrm{hBN}$. They are believed to be originated from the individual hBN nanoparticles, which are located on the surface of the coating, as a result of their surface modification.

\subsection{Properties of coatings}

Glass coatings obtained by sol-gel method and cured at $500{ }^{\circ} \mathrm{C}$ were characterized. Their thickness, adhesion, newton hardness, water contact angle and friction coefficients were determined. The results are presented in Table 1.

Adhesion properties of the coatings were evaluated by multicross cutter and it was seen that there was no peel off from the coatings. Therefore the coatings were categorized as $5 \mathrm{~B}$, indicating that the surface preparation of the stainless steel substrates and coating procedure were appropriate. Addition of $2 \% \mathrm{hBN}$ did not affect the adherence characteristics of the coatings. Thickness and hardness of the coatings were in $1.3-2.5 \mu \mathrm{m}$ and 2-3.5 $\mathrm{N}$ range, respectively. The coatings were seen to be thinner when higher spin speeds are utilized during spin coating. Water contact angle measurements indicates that the coatings had hydrophilic character, with contact angles of $8-10^{\circ}$. Curing at $500{ }^{\circ} \mathrm{C}$ is believed to result in removal of hydrophobic groups from the surfaces, which lead to hydrophilic character. Visual comparison of the uncoated and coated steel plates after keeping for 22 days in salt spray cabin revealed that the glass coatings increased the corrosion resistance. The friction coefficients of the plain coatings were in $0.15-0.20$ range. Addition of FTS modified hBN nanoparticles resulted in a slight decrease in the friction coefficients. These samples presented friction coefficients in $0.10-0.15$ range.

\section{Conclusion}

Sol-gel method was utilized for obtaining glass coatings containing hBN nanoparticles on steel substrates. In some coatings, fluorosilane modified hBN nanoparticles were utilized with the aim of attaining richer distribution of hBN on the surface of the coatings. Enrichment of the hBN nanoparticles on the surfaces was confirmed by SEM and AFM examinations. Slight reduction in friction coefficient was attained by the introduction of fluorosilane modified hBN into glass coatings. The decrease in the friction coefficient was minor, since plain coatings had low friction coefficients. It has been shown that surface modification of nanoparticles is an effective tool to tailor the structure and properties of nanocomposite coatings that are prepared by the sol-gel method.

\section{Acknowledgments}

Authors are grateful to The Scientific and Technological Research Council of Turkey (TUBITAK) for supporting this study with the Project Number 110M722.

\section{References}

[1] N. Kiraz, Ö. Kesmez, E. Burunkaya, L. Budama, B. Acar, M. Asiltürk, H. E. Çamurlu, E. Arpaç, Antibacterial glass films prepared on metal surfaces by sol-gel method, J. Sol.-Gel Sci. Technol. 56 (2010) 227-235.

[2] N. Kiraz, E. Burunkaya, Ö. Kesmez, M. Asiltürk, H.E. Camurlu, E. Arpac, Sol-gel synthesis of 3-(triethoxysilyl)propylsuccinicanhydride containing fluorinated silane for hydrophobic surface applications, J. Sol.-Gel Sci. Technol. 56 (2010) 157-166.

[3] E. Burunkaya, N. Kiraz, Ö. Kesmez, M. Asiltürk, H.E. Çamurlu, E. Arpaç, Sol-gel synthesis of IPTES and D10H consisting fluorinated silane system for hydrophobic applications, J. Sol.-Gel Sci. Technol. 56 (2010) 99-106.

[4] L.M. Stark, I. Smid, A.E. Segall, T.J. Eden, J. Potter, Self-lubricating cold-sprayed coatings utilizing microscale nickel-encapsulated hexagonal boron nitride,
Tribol. T 55 (5) (2012) 624-630.

[5] M. Guglielmi, G. Kickelbick, A. Martucci, Sol-Gel Nanocomposites, Springer, New York, 2014.

[6] H. Schmidt, M. Akarsu, T.H.S. Müller, K. Moh, G. Schafer, D.J. Strauss, M. Naumann, The formation of gradients in wet deposited coatings with photocatalytically active nanoparticles, Res. Chem. Intermediat. 31 (4-6) (2005) 535-553.

[7] H. Schmidt, M. Naumann, T.S. Müller, M. Akarsu, Application of spray techniques for new photocatalytic gradient coatings on plastics, Thin Solid Films 502 (2006) 132-137.

[8] Y. Zhu, F. Piscitelli, G.G. Buonocore, M. Lavorgna, E. Amendola, L. Ambrosio, Effect of surface fluorination of tio2 particles on photocatalitytic activity of a hybrid multilayer coating obtained by sol-gel method, ACS Appl. Mater. Interfaces 4 (2012) 150-157.

[9] H. Vaghari, Z. Sadeghian, M. Shahmiri, Investigation on synthesis, characterization and electrochemical properties of $\mathrm{TiO}_{2}-\mathrm{Al}_{2} \mathrm{O}_{3}$ nanocomposite thin film coated on 316 L stainless steel, Surf. Coat. Technol. 205 (2011) 5414-5421.

[10] N. Ay, I. Töre, Pressureless sintering of hexagonal boron nitride powders, Mater. Sci. Forum 554 (2007) 207-212.

[11] H.E. Çamurlu, N. Sevinç, Y. Topkaya, Role of boron carbide in carbothermic formation of hexagonal boron nitride, J. Mater. Sci. 41 (2006) 4921-4927.

[12] H.E. Çamurlu, N. Sevinç, Y. Topkaya, Effect of calcium carbonate addition on carbothermic formation of hexagonal boron nitride, J. Eur. Ceram. Soc. 28 (2008) 679-689.

[13] H.E. Çamurlu, Y. Topkaya, N. Sevinç, Catalytic effect of alkaline earth oxides on carbothermic formation of hexagonal boron nitride, Ceram. Int. 35 (2009) 2271-2275.

[14] H.E. Çamurlu, Effect of $\mathrm{Na}_{2} \mathrm{CO}_{3}$ on hexagonal boron nitride prepared from urea and boric acid, Ceram. Int. 37 (2012) 1993-1999.

[15] A.A. Özkenter, H.E. Camurlu, N. Sevinç, Effects and roles of $\mathrm{CaCO}_{3}$ and $\mathrm{CaO}$ in carbothermic formation of h-BN, J. Ceram. Process. Res. 13 (2012) 533-540.

[16] H.E. Çamurlu, A. Gençer, B. Becer, Ş. Özdoğan, Catalytic effect of potassium carbonate on carbothermic production of hexagonal boron nitride, Ceram. Int. 39 (2013) 8589-8595.

[17] H.E. Çamurlu, A. Gençer, B. Becer, Comparative catalytic study on the carbothermic formation of hexagonal boron nitride with Li, Na, K and Ca carbonates, J. Mater. Sci. 49 (2013) 371-379.

[18] K.S. Lee, Y.S. Kim, M. Tosa, A. Kasahara, K. Yosihara, Hexagonal boron nitride film substrate for fabrication of nanostructures, Appl. Surf. Sci. 415 (9) (2001) $169-170$

[19] Y.M. Chong, Q. Ye, Y. Yang, W.J. Zhang, I. Bello, S.T. Lee, Tribological study of boron nitride films, Diam. Relat. Mater. 19 (2010) 654-660.

[20] K. Nakamura, T. Sasaki, Boron nitride films prepared by MOCVD, J. Solid State Chem 154 (2000) 101-106.

[21] Z. Liu, Y. Gong, W. Zhou, L. Ma, J. Yu, C.J. Idrobo, J. Jung, H.A. MacDonald, R. Vajtai, J. Lou, M.P. Ajayan, Ultra thin high $\neg$ temperature oxidation $\neg$ resistant coatings of hexagonal boron nitride, Nat. Commun. (2013), http://dx.doi.org/ $10.1038 /$ ncomms3541.

[22] J. Hou, G. Li, N. Yang, L. Qin, M.E. Grami, Q. Zhang, N. Wang, X. Qu, Preparation and characterization of surface modified boron nitride epoxy composites with enhanced thermal conductivity, RSC Adv 4 (2013) 44282-44290.

[23] E. Husain, N.T. Narayanan, J.J. Taha-Tijerina, S. Vinod, R. Vajtai, M.P. Ajayan, Marine corrosion protective coatings of hexagonal boron nitride thin films on stainless steel, ACS Appl. Mater. Interfaces, 5, (2013) 4129-4135.

[24] O.A. Leon, M.H. Staia, H.E. Hintermann, Wear mechanism of Ni-P-BN (h) composite autocatalytic coatings, Surf. Coat. Technol. 200 (2005 $1825-1829$.

[25] S. Zhang, J. Zhou, B. Guo, H. Zhou, Y. Pu, J. Chen, Friction and wear behavior of laser cladding Ni/hBN self-lubricating composite coating, Mat. Sci. Eng. A-Struct. 491 (2008) 47-54.

[26] S. Zhang, J. Zhou, B. Guo, H. Zhou, Y. Pu, J. Chen, Preparation and characterization of reactively sintered $\mathrm{Ni}_{3} \mathrm{Al}-\mathrm{HBN}-\mathrm{Ag}$ composite coating on Ni-based super alloy, J. Alloy. Compd. 473 (2008) 462-466.

[27] E. Burunkaya, Ö. Kesmez, N. Kiraz, H.E. Camurlu, M. Asiltürk, E. Arpac, Hydrophilic hybrid $\mathrm{SiO}_{2}$ :polyethylene glycol-3-isocyanato-propyltrietoxysilane nanocomposite films, Thin Solid Films 522 (2012) 238-246.

[28] Ö. Kesmez, E. Burunkaya, N. Kiraz, H.E. Çamurlu, M. Asiltürk, E. Arpaç, Effect of acid, water and alcohol ratios on sol-gel preparation of antireflective amorphous $\mathrm{SiO}_{2}$ coatings, J. Non-Cryst. Solids 357 (2011) 3130-3135.

[29] Ö. Kesmez, N. Kiraz, E. Burunkaya, H.E. Çamurlu, M. Asiltürk, E. Arpaç, Effect of amine catalysts on preparation of nanometric $\mathrm{SiO}_{2}$ particles and antireflective films via sol-gel method, J Sol.-Gel Sci. Technol. 56 (2010) 167-176.

[30] Ö. Kesmez, H.E. Çamurlu, E. Burunkaya, E. Arpaç, Preparation of antireflective $\mathrm{SiO}_{2}$ nanometric films, Ceram. Int. 36 (2010) 391-394.

[31] H.E. Camurlu, Ö. Kesmez, E. Burunkaya, N. Kiraz, Z. Yeşil, M. Asiltürk, E. Arpaç Sol-gel thin films with anti-reflective and self-cleaning properties, Chem. Paper 66 (2010) 461-471.

[32] E. Burunkaya, Ö. Kesmez, N. Kiraz, H.E. Camurlu, M. Asiltürk, E. Arpac, $\mathrm{Sn}^{4+}$ or $\mathrm{Ce}^{3+}$ doped $\mathrm{TiO}_{2}$ photocatalytic nanometric films on antireflective nano-SiO coated glass, Mater. Chem. Phys. 120 (2010) 272-276.

[33] Ö. Kesmez, H.E. Çamurlu, E. Burunkaya, E. Arpaç, Sol-gel preparation and characterization of anti-reflective and self-cleaning $\mathrm{SiO}_{2}-\mathrm{TiO}_{2}$ double layer nanometric films, Sol. Energy Mater. Sol. C 93 (2009) 1833-1839.

[34] J. Wen, G.L. Wilkes, Organic/inorganic hybrid network materials by the sol-gel approach, Chem Mater 8 (1996) 1667-1681.

[35] P. Fabbri, M. Messori, M. Montecchi, S. Nannarone, L. Pasquali, F. Pilati, 
C. Tonelli, M. Toselli, Perfluoropolyether-based organic-inorganic hybrid coatings, Polymer 47 (1996) 1055-1062.

[36] L. Mascia, T. Tang, Ceramers based on crosslinked epoxy resins-silica hybrids: low surface energy systems, J. Sol.-Gel Sci. Technol. 13 (1998) 405-408.

[37] H.E. Camurlu, S. Mathur, O. Arslan, E. Akarsu, Modification of hexagonal boron nitride nanoparticles with fluorosilane, Ceram. Int. 42 (2016) 6312-6318.

[38] X. Zhang, Y. Wu, S. He, D. Yang, Structural characterization of sol-gel composites using TEOS/MEMO as precursors, Surf. Coat. Technol. 201 (2007) 6051-6058.
[39] M. Lattemann, K. Sell, J. Ye, P.A.O. Persson, S. Ulrich, Stress reduction in nanocomposite coatings consisting of hexagonal and cubic boron nitride, Surf. Coat. Technol. 200 (2006) 6459-6464.

[40] F. Rubio, J. Rubio, J.L. Oteo, A. FT-IR, Study of the hydrolysis of tetraethylorthosilicate (TEOS), Spectrosc. Lett. 31 (1998) 199-219.

[41] E. da, C. Mattos, E.D. Moreira, M.F. Diniz, R.C.L. Dutra, G. da Silva, K. Iha, U. Teipel, Characterization of polymer-coated RDX and HMX particles, Propellants Explos. Pyrotech. 33 (2008) 44-50. 